\title{
PROFILE OF HAEMOPHILIA PATIENTS IN MANIPUR
}

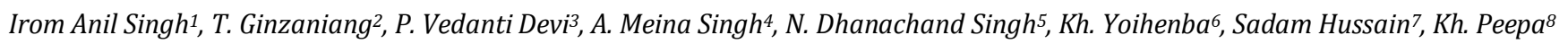

${ }^{1}$ Assistant Professor, Department of Medicine, JNIMS, Imphal, Manipur, India. ${ }^{2}$ Associate Professor, Department of Medicine, JNIMS, Imphal, Manipur, India.

${ }^{3}$ Assistant Professor, Department of Medicine, JNIMS, Imphal, Manipur, India.

${ }^{4}$ Professor, Department of Transfusion Medicine, RIMS, Imphal, Manipur, India.

${ }^{5}$ Senior Resident, Department of Medicine, JNIMS, Imphal, Manipur, India.

${ }^{6}$ Senior Resident, Department of Medicine, JNIMS, Imphal, Manipur, India.

${ }^{7}$ Postgraduate Trainee, Department of Medicine, JNIMS, Imphal, Manipur, India.

${ }^{8}$ Postgraduate Trainee, Department of Medicine, JNIMS, Imphal, Manipur, India.

\section{BACKGROUND}

The deficiency of blood coagulation factor VIII (F-VIII) and factor IX (F-IX) are called Haemophilia A and B respectively. They are inherited as X-linked recessive traits. They are the most common hereditary haemorrhagic disorders. Patients have increased bleeding tendency especially the joints, muscles and after any trauma. The treatment for haemophilia is by providing factors VIII and IX.

\section{MATERIALS AND METHODS}

The aim of the study was to know various clinical manifestations of the disease in Manipur. The study was conducted in the Department of Medicine, Jawaharlal Nehru Institute of Medical Sciences, Imphal from 1st August 2017 till 31 st May 2018. The study design was a descriptive study. Any patient who is diagnosed as haemophilia A or B was included in the study. Patients who had any other bleeding disorder, refused to give consent for the inclusion in the study and patients belonging to other states of India were excluded from the study.

\section{RESULTS}

Sixty-five patients presented with complaints of increased bleeding. Thirty-five patients were included in the analysis. Out of these 35 patients, there were 30 (85.7\%) cases of Haemophilia A and 5 (14.53\%) cases of Haemophilia B. There was no family history in 25 cases $(71.43 \%)$. The patients in the study had presented pain and swelling in the joints in majority consisting of 19 cases (54.29). Not a single patient was in prophylaxis due to lack of adequate factors.

\section{CONCLUSION}

Early treatment after any bleeding episodes and prophylaxis will be essential in preventing various complications.

\section{KEY WORDS}

Haemophilia A, Haemophilia B, Anti-Haemophilic Factors.

HOW TO CITE THIS ARTICLE: Singh IA, Ginzaniang T, Devi PV, et al. Profile of haemophilia patients in Manipur. J. Evolution Med. Dent. Sci. 2018;7(33):3653-3656, DOI: 10.14260/jemds/2018/820

\section{BACKGROUND}

There are many inherited bleeding disorders due to deficiency of coagulation factors. Among them, the deficiency of blood coagulation factor VIII (F-VIII) and factor IX (F-IX) are called Haemophilia A and B respectively. They are inherited as $\mathrm{X}$-linked recessive traits. They are the most common hereditary haemorrhagic disorder. They along with Von Willebrand's disease constitute $95 \%$ to $97 \%$ of all the inherited deficiencies of coagulation factors. Molecular analysis, carrier detection and prenatal diagnosis is an important step in the prevention of haemophilia in developing countries.(1),(2)

In the past, this illness was often neglected. However, in the last three decades, safe and effective treatment is

'Financial or Other Competing Interest': None.

Submission 30-06-2018, Peer Review 31-07-2018,

Acceptance 06-08-2018, Published 13-08-2018.

Corresponding Author:

T. Ginzaniang,

Department of Medicine,

JNIMS, Porompat, Imphal East-795005,

Manipur, India.

E-mail: gindr.7@gmail.com

DOI: $10.14260 /$ jemds $/ 2018 / 820$

(c) (i) $\$$ developed for the illness. Gene therapy has been able to cure patients suffering from haemophilia in the third millennium. Four-fifths of the world's haemophiliacs are in India, however, due to poor socio-economic conditions majority of patients still receive no treatment at all.(2) Among the haemophiliacs, the haemophilia $\mathrm{A}$ is more common and represents $80-85 \%$ of total haemophilia. It is about 7 times more than haemophilia B. This illness is seen in about 1 in 25,000 male births in developed countries like the US whereas in India it is 1 in $30,000-60,000$ male births However, all races and economic groups are affected equally.(3) Based on the WFH's (World Federation of Haemophiliac) annual global surveys, currently there are approximately 400,000 patients suffering from the disease.(4),(5)

The approach to the diagnosis of haemophilia is done from the history of bleeding, clinical findings, family history and demonstration of factor deficiency. The disease has a history of easy bruising in the early childhood, spontaneous bleeding into the joint, muscles and soft tissue without any apparent causes and excessive bleeding after trauma or surgery. Family history is usually available in about twothirds of all the patients. The diagnosis of the illness is 
confirmed by the demonstration of factor deficiency of F-VIII or F-IX.(5)

According to the level of factor deficiency, the disease can be classified as severe $(<1 \%)$, moderate $(1-5 \%)$ and mild $>$ (5 - 40\%). The severe disease usually presents with spontaneous bleeding into the joints and muscle. In case of moderate disease, bleeding can occur with minor trauma or surgery occasionally. The patients with mild disease have severe bleeding only during major surgery or trauma. The major site of bleeding is the hinged joints like ankle, knee and elbows comprising $70-80 \%$ and muscle consisting 10 $20 \%$ (5) $^{(5)}$

Patients usually can recognise the early sign of bleeding in them just like an aura. The main target for the care of haemophilia is to prevent and treat bleeding with specific anti-haemophilic factors as soon as possible. The factors should be given ideally within 2 hours of bleeding.(6) However, it should be given immediately in the case of lifethreatening bleeding like in the head and neck, brain and gastrointestinal tract.(7) In cases of unavailability of the factors, the patients may be treated with desmopressin (DDAVP). DDAVP can raise F-VIII adequately 3 - 6 times from baseline levels and it helps to control bleeding especially in the mild and moderate cases. ${ }^{(8)}$

\section{Aim and Objective}

To study the profile of patients suffering from haemophilia in Manipur.

\section{MATERIALS AND METHODS}

The study was conducted in the Department of Medicine, Jawaharlal Nehru Institute of Medical Sciences, Imphal from $1^{\text {st }}$ August 2017 till 31st May 2018. The study design was a descriptive study. During the study period, the patients presenting with complaints of increased bleeding were eligible for the inclusion in the study. The inclusion criteria of the study were any patient who is diagnosed with haemophilia A or B as per the standard guidelines having a factor assay report. Exclusion criteria included any patient who has any other bleeding disorder, refused to give consent for the inclusion in the study and the patient belonging to other states of India. The patients were classified as a mild, moderate and severe disease based on the levels of factor present in the patients which are $5-40 \%, 1-5 \%$ and $<1 \%$ respectively. The presence of inhibitors was suspected if the patient does not respond to the factors. If the inhibitor was suspected clinically, then inhibitor screening was done by doing a PTT test within 30 minutes of factor injection. If there was prolonged PTT test, Bethesda inhibitor screening was planned to confirm the presence of inhibitors.

The recombinant factors VIII and IX supplied by the World Haemophilia Federation through Haemophilia Federation of India. Since the factors were not sufficiently available in Manipur, all the patients were given antihaemophilic factors as an on-demand basis. The dose requirement was calculated based on the guidelines of the World Federation of Haemophilia. Since the factors were not adequately available, most of the cases were given for a shorter duration. If the patient comes for joint pain or muscle bleed, one or two doses were given. In the case of unrelieved symptoms, additional doses were given. In case of intraabdominal or intracranial bleeding, factors were given for 5 days and reassessed after 5 days. If the symptoms have subsided, the dose was reduced to $50 \%$ of the initial doses. And the factors were stopped after 7 days. The patients having joint deformity were sent for rehabilitation. Due to the scarcity of factors, patients were not given factor prophylaxis before the rehabilitation. However, in case of any discomfort following the rehabilitation factors were given. Factors were also given before any elective procedures. The statistical analysis could not be done due to the small size of the study.

\section{RESULTS}

During the study period, 65 patients presented with complaints of increased bleeding. We excluded 30 patients as they were diagnosed with other bleeding disorder or not a domicile of Manipur. Five patients were from other parts of India who were residing in Manipur for service or some other purpose. Five patients were diagnosed as suffering from Von Willebrand's disease and one patient had factor XIII deficiency. Acquired haemophilia A was diagnosed in 2 female patients. Seventeen patients were diagnosed with immune thrombocytopenia. After excluding 30 cases, 35 patients were included in the analysis. Out of these 35 patients, there were $30(85.7 \%)$ cases of Haemophilia A and 5 $(14.53 \%)$ cases of Haemophilia B. The disease was seen highest in the age group of 11 - 20 years consisting $40 \%$ of all the cases followed by 1 - 10 years (31.43\%) and 21 - 30 years $(22.86 \%)$. The illness was found to be low in the age group above 30 years $(5.72 \%)$. The family history was present in 10 patients comprising of 10 cases $(28.57 \%)$. There was no family history in 25 cases $(71.43 \%)$. In our study, the majority of cases belong to severe category consisting of 18 cases $(51.42 \%)$. It was followed by a moderately severe category with 14 cases (40\%). The mild cases were seen in 3 cases $(8.57 \%)$ (Table No. 1). Majority of the haemophilia cases were seen in Imphal district comprising of 12 cases (34.29\%). It was followed by Thoubal district with 7 cases (20\%), Bisenpur district with 5 cases (14.29\%), Senapati and Churchanpur districts with 3 cases each (8.57\%), Tamenglong and Ukhrul districts with 2 cases $(5.7 \%)$ and Chandel district with 1 case (2.57\%) (Fig. No. 1).

The patients in the study had presented pain and swelling in the joints in majority consisting of 19 cases (54.29\%). It was followed by prolonged bleeding following trauma or cuts, gum bleeding and swelling in the body in 7 cases $(20 \%)$ each. Intracranial bleeding was seen in 2 cases (5.71\%). One patient had intraabdominal mass due to bleeding in the study. In 15 cases, there was joint deformity (42.86\%) (Fig. No. 2).

The patients were treated with factor supplied by the World Haemophilia Federation (WHF) through Haemophilia Federation of India. Four patients had bought antihaemophilic factors when the factors were out of stock. Rest of the patients were utilising the factors as provided from time to time. Majority of the factors were extended half-life factors Eloctate (F-VIII) and alprolix (F-IX) in $65.7 \%$ of cases. Other third generation anti-haemophilic factor Gene in $34.29 \%$. Plasma-derived factors were used when the supply from the WHF was not available in $8.56 \%$. Not a single patient was in prophylaxis due to lack of adequate factors. The patients were treated on an on-demand basis in $85.71 \%$. However, in cases of intracranial bleeding and intraabdominal bleeding they were given on daily basis for a period of 4 - 5 days in $14.29 \%$ cases. The usual time for factor from the onset of pain or bleeding was 24 hours in 30 
(85.71\%) patients. Only in the remaining 5 (14.29\%) patients, they reported within 12 hours (Table No. 2).

\begin{tabular}{|c|c|}
\hline Baseline Characteristics & $\mathbf{( n = 3 5 ) ( \% )}$ \\
\hline Age Group & $11(31.43)$ \\
$1-10$ & $14(40.00)$ \\
$11-20$ & $8(22.86)$ \\
$21-30$ & $2(5.72)$ \\
$>30$ & $7(20.00)$ \\
\hline Family History & $1(2.86)$ \\
Sibling & $2(5.71)$ \\
Maternal uncle & $25(71.43)$ \\
Maternal cousins & $30(85.71)$ \\
Nil & $5(14.29)$ \\
\hline Haemophilia A & $3(8.57)$ \\
Haemophilia B & $14(40.00)$ \\
Severity & $18(51.42)$ \\
\hline Mild & Moderate \\
Severe & Table 1. Baseline Characteristics \\
\hline
\end{tabular}

\begin{tabular}{|c|c|}
\hline Treatment & N= 35 (\%) \\
\hline $\begin{array}{c}\text { Source of Factor } \\
\text { WHF (HFI) } \\
\text { Self }\end{array}$ & $35(100)$ \\
$2(5.86)$ \\
\hline Time to Factor Administration \\
12 hours \\
48 hours & 0 \\
Number of Doses & $34(97.14)$ \\
Once & $1(2.86)$ \\
More than three days & $30(85.71)$ \\
Types of the Factor used & $5(14.29)$ \\
Extended half-life (Eloctate and \\
Alprolix) \\
Recombinant factor standard half- \\
life (VIII and IX) \\
\hline \multicolumn{2}{|c|}{ Table 2. Treatment of Patients } \\
\hline \multicolumn{2}{|c|}{} \\
\hline
\end{tabular}

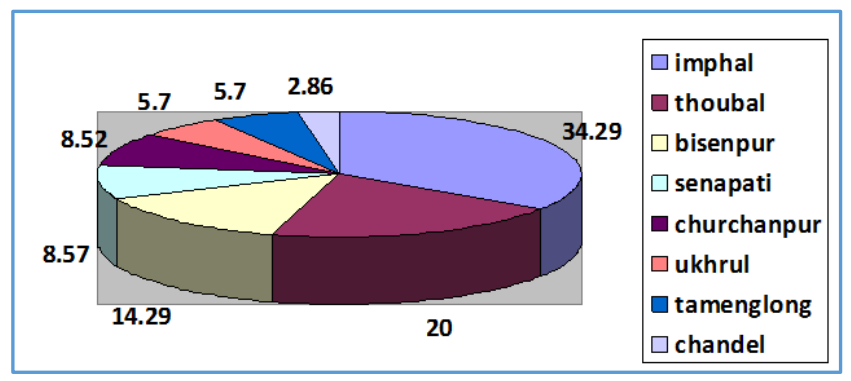

Figure 1. Percentage of Haemophilia patients in various district of Manipur

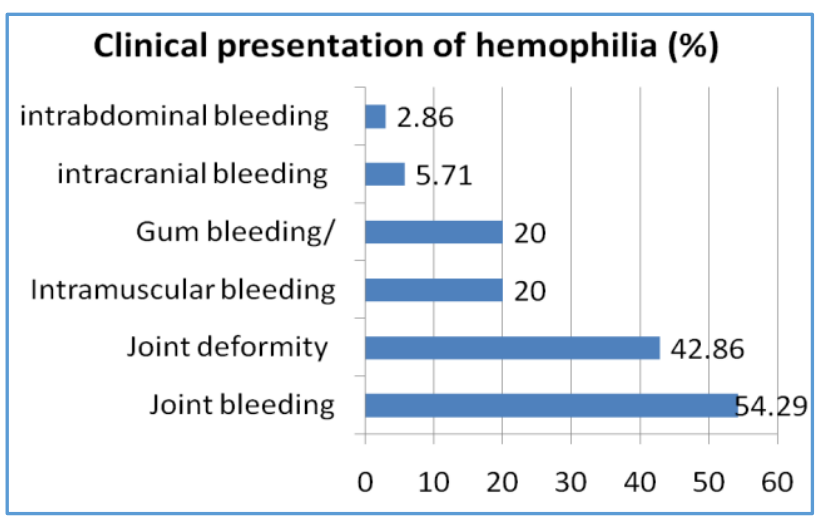

Figure 2. Clinical Presentations

\section{DISCUSSION}

Haemophilia has been reported to be about 1 in 25,000 male births in US and 1 in 30,000 - 60,000 in India.(3) According to 2011 census Manipur has a population of 28.56 lakhs, of which 1,438,586 were males.(9) So, approximately 2 in 100,000 male births are suffering from haemophilia in Manipur. This is quite less compared to other places. There is a lack of awareness among the various communities about the disease in Manipur. This could be the reason for the lesser number of the disease in Manipur. Haemophilia A is about 80$85 \%$ of the total haemophilia populations.(5) Likewise, in our study Haemophilia A comprised $85 \%$ of all the haemophilia cases in Manipur.

It was reported that spontaneous mutation of F8 and F9 genes responsible for haemophilia may take place in about $1 / 3$ of cases. So there may be $30 \%-40 \%$ cases where there is no prior family history.(5) In our study, we found nearly $2 / 3^{\text {rd }}$ of cases with no prior family history. This could be due to the fact that the number of patients is less.

The WFH reported haemarthrosis (70 - 80\%), muscle haematoma $(10-20 \%)$, other bleeding (5 - 10\%) and intracranial bleeding as $<5 \%$.(5) Our study had observed lesser haemarthrosis (54.29\%). This could be related to the severity of haemophilia that we have in Manipur. On the other side the bleeding was similar for muscular bleeding, intracranial bleeding and bleeding from other sources. In most adult haemophiliac patients, they experience limitations in activities of daily living due to chronic articular pain. Paracetamol and COX-2 inhibitors are the drug of choice for the treatment of chronic articular pain. When they do not work, we may choose second-line treatment like intraarticular steroids and hyaluronic acids. Along with these drugs, rehabilitation and physiotherapy may be used.(10) In our study, the patients with pain were controlled with paracetamol and tramadol. Two patients were receiving rehabilitation.

Fischer et al had reported the median age of prophylaxis as 5.5 years. In their study, majority (69\%) interrupted prophylactic treatment. Those patients who stopped prophylaxis had more joint problems. However, it remained unclear about indefinite prophylaxis, especially when they reach adulthood. Some data had suggested that some adults may do well even after stopping prophylaxis.(11) In our study, majority of the patients were only receiving on-demand treatment. As a result of which there were more cases of joint bleeding and joint deformity. Luchtman-Jones L et al had done a study to see the effect of short course of prophylaxis in haemophilia. These authors have reported on the usefulness of short-term prophylaxis lasting 4 - 8 weeks. They have found that with this approach the repeated bleeding cycle into target joints was interrupted.(12) Previous studies have shown that prophylaxis does not reverse the established joint damage. However, the prophylaxis decreases the bleeding rate. It may also reduce the disease progression and improve the quality of life. Since the prophylaxis is very costly, the developing countries find it difficult to provide prophylaxis properly. So in a country like India and our state, lower dose of prophylaxis given more frequently may be an effective option. WFH is already recommended for resource poor countries like India to get prophylaxis once a week. This can be escalated during bleeding.(5) In our study, two patients received a short course of weekly prophylaxis for three 
weeks. One patient had reported better quality of life and reduced frequency of bleeding after a short course therapy. The second patient did not have the desired response till the second week. However, we should have given more weeks if factors were adequately available. So in a place like Manipur, we may try for low dose and less frequency prophylaxis. This may reduce the bleeding rate and associated complications.

\section{The Strength of the Study}

This is the first report of haemophilia patients from Manipur. Limited data are available with respect to the various aspects of the disease. This study gives an insight about the various problems faced by the patients. This may help the National bodies in making various programmes in the state.

\section{Limitation of the Study}

The sample size is less as a result of which statistical analysis could not be performed.

\section{CONCLUSION}

Early detection of the disease is very essential. Awareness among the people and family about the diseases is still less. So, awareness programs about the prophylaxis, treatment will help the people with haemophilia in the long run. Early treatment after any bleeding episodes and prophylaxis will be essential in preventing various complications.

\section{REFERENCES}

[1] Peyvandi F, Jayandharan G, Chandy M, et al. Genetic diagnosis of Haemophilia and other inherited bleeding disorders. Haemophilia 2006;(12 Suppl 3):82-9.

[2] Mannucci PM. Haemophilia: treatment options in the twenty-first century. J Thromb Haemost 2003;1(7):1349-55.

[3] Philip J, Sarkar RS, Kumar S, et al. Factor IX deficiency (Christmas disease). Med J Armed Forces India 2012;68(4):379-80.
[4] Stonebraker JS, Bolton-Maggs PHB, Soucie JM, et al. A study of variations in the reported haemophilia: a prevalence around the world. Haemophilia 2010;16(1):20-32.

[5] Srivastava A, Brewer AK, Mauser-Bunschoten EP, et al. Guidelines for the management of haemophilia. $2^{\text {nd }}$ edn. Blackwell Publishing Ltd., 2012. www.wfh.org.

[6] Ingram GI, Dykes SR, Creese AL, et al. Home treatment in haemophilia: clinical, social and economic advantages. Clinical Lab Haematol 1979;1(1):13-27. https://onlinelibrary.wiley.com/doi/pdf/10.1111/j.1 365-2257.1979.tb00586.x

[7] Singleton T, Kruse-Jarres R, Leissinger C. Emergency department care for patients with haemophilia and von Willebrand disease. J Emerg Med 2010;39(2):15865.

[8] Castaman G, Mancuso ME, Giacomelli SH, et al. Molecular and phenotypic determinants of the response to desmopressin in adult patients with mild Haemophilia A. J Thromb Haemost 2009;7(11):182431.

[9] Manipur population sex ratio in manipur literacy rate data. [cited 2018 Jun 28] https://www.census2011.co.in/census/state/manipu r.html

[10] Rodriguez-Merchan EC. Treatment of chronic articular pain in adults with Haemophilia. Cardiovasc Hematol Disord Drug Targets 2018.

[11] Fischer K, Van Der Bom JG, Prejs R, et al. Discontinuation of prophylactic therapy in severe Haemophilia: incidence and effects on outcome. Haemophilia 2001;7(6):544-50.

[12] Luchtman-Jones L, Valentino LA, Manno C, et al. Considerations in the evaluation of Haemophilia patients for short-term prophylactic therapy: a paediatric and adult case study. Haemophilia 2006;12(1):82-6. 